\title{
Mortality in England and Wales attributable to current alcohol consumption
}

\author{
A Britton, $\mathrm{K}$ McPherson
}

\begin{abstract}
Study objective-To estimate the number of deaths attributable to current alcohol consumption levels in England and Wales by age and sex.

Design-Epidemiological approach using published relative risks and population data.

Setting-England and Wales.

Main outcome measures-Numbers of deaths by age and sex and years of life lost for alcohol related conditions.

Results-Because of the cardioprotective properties of alcohol, it is estimated that there are approximately $2 \%$ fewer deaths annually in England and Wales than would be expected in a non-drinking population. This proportion varies greatly by age and sex and only among men aged over 55 years and women aged over 65 years is there likely to be found a net favourable mortality balance. It is also estimated that there were approximately 75000 premature years of life lost in England and Wales in 1996 attributable to alcohol consumption. The main causes of alcohol attributable mortality among the young include road traffic fatalities, suicide and alcoholic liver disease.

Conclusions-At a population level, current alcohol consumption in England and Wales may marginally reduce mortality. However, the benefit is disproportionately found among the elderly. Estimating alcohol attributable mortality by age and sex may be a useful indicator for developing alcohol strategies. More research into the possible effect modifications of pattern of consumption, beverage type, age and gender will enable these estimates to be improved.
\end{abstract}

(F Epidemiol Community Health 2001;55:383-388)

Health Promotion

Research Unit, London

School of Hygiene and

Tropical Medicine,

Keppel Street, London

WC1E 7HT, UK

A Britton

Cancer and Public Health Unit, London

School of Hygiene and

Tropical Medicine

$\mathrm{K}$ McPherson

Correspondence to: Annie Britton

(annie.britton@1shtm.ac.uk)

Accepted for publication 1 February 2001
From the public health perspective, alcohol provides many challenges. Unlike most other mood altering substances, it is legal, socially acceptable and extremely widely used, thus making any control policies complicated. Moreover, it is widely recognised that alcohol can bring significant benefits as well as harm to individuals and societies. It can not only be a life enhancing convivial habit, but when consumed in moderation, it has a protective effect against coronary heart disease ${ }^{1}$ and possibly ischaemic stroke. ${ }^{23}$ Its benefits may, however, be outweighed by an increased risk of other diseases (including cirrhosis of the liver, pancreatitis, upper aerodigestive cancers, and alcohol psychoses) and an increased risk of violence and accidents. ${ }^{4}$
For certain sections of society the balance of risks and benefits, measured here in terms of deaths attributable to alcohol consumption, may result in a net number of deaths "prevented" or "delayed". This is most likely to be found among those with an underlying higher risk of heart disease, such as middle aged and elderly men. Younger men, on the other hand, may experience a net aggregate excess of alcohol attributable deaths largely because of their higher rates of weekly alcohol consumption and also their higher rates of accidents and violence compared with older men. For women the balance is complicated by the addition of a possible association between alcohol consumption and the incidence of breast cancer. ${ }^{6}$ If at all, net positive balances will be found among postmenopausal women when their background coronary heart disease risks are increased.

Such calculations on aggregated deaths are useful to inform sensible drinking guidelines for different sections of society. Clearly, the estimation of alcohol attributable deaths is only part of the picture as the toll of alcohol related harm includes additional damage to the physical and mental health of the drinker, as well as to their families, friends and others in society through accidents, crimes, violence and impaired working capacity. On the other hand quality of life improvement resulting from moderate drinking may be a very important social benefit. ${ }^{7}$

\section{Methods}

Mortality data in England and Wales for 1996 were obtained from the Office for National Statistics. ${ }^{8}$ The numbers of deaths for 26 relevant conditions, using the International Classification of Diseases version 9 (ICD-9), were extracted by age and sex. The relative risks used in this analysis, shown in tables 1 and 2 , were mainly derived from a large metaanalysis (123 studies) of available international epidemiological evidence by Corrao et al. ${ }^{9}$ Studies were assessed for quality (study design, alcohol consumption measurement, data analysis methods and adjustment for confounders) and separate risk functions were given by gender, area (Mediterranean versus non-Mediterranean), study design (casecontrol versus cohort studies) and outcome (incidence versus deaths) where appropriate. The relation between alcohol and ischaemic heart disease (IHD) was not reported in this meta-analysis as the authors were only concerned with harmful consequences. However, a subsequent meta-analysis by the same authors was published the following year. ${ }^{10}$

Alcohol consumption data were collected in the 1998 Health Survey for England. ${ }^{11}$ This 
Table 1 The alcohol risk functions based on meta-analyses by Corrao et al and English et al

\begin{tabular}{|c|c|}
\hline Condition & Effects of alcohol \\
\hline Rectal cancer & $\log R R=0.0042 . a l c^{\star}(+0.0282$. alc if female $\dagger)$ \\
\hline Oropharyngeal cancer & $\log R R=0.0348$. alc -0.0001. alc`2 $(+0.0015$ alc if female -0.0067 alc if non-Med. country $\ddagger)$ \\
\hline Oesophageal cancer & $\log R R=0.0186$. alc $-0.0000001 . a l{ }^{\wedge} 3(-0.0028$. alc if non-Med. country $)$ \\
\hline Liver cancer & $\log R R=0.0074 . \mathrm{alc}-0.00001 . \mathrm{alc}{ }^{\wedge} 2$ \\
\hline Laryngeal cancer & $\log R R=0.0197$. alc -0.00000002. alc $^{\wedge} 3(-0.0120$. alc if non-Med. country) \\
\hline Breast cancer & $\log R R=0.0123$ alc $(-0.0046$.alc if non-Med. country $)$ \\
\hline Colon cancer & $\log R R=0.0014$. alc $(+0.0116$. alc if cohort studies $\S)$ \\
\hline IHD & $\log \mathrm{RR}=0.0011 . \mathrm{alc}-1.0650 \mathrm{Valc}(+0.0062 \mathrm{alc}$ if female $)$ \\
\hline Haemorrhagic stroke & $\log R R=0.0150 . \mathrm{alc}$ \\
\hline Essential hypertension & $\log R R=0.0142 . \mathrm{alc}$ \\
\hline Chronic pancreatitis & $\log \mathrm{RR}=0.0116 . \mathrm{alc}$ \\
\hline Alcholic liver disease & $100 \%$ deaths attributable to alcohol consumption \\
\hline Non-dependent abuse of alcohol & $100 \%$ deaths attributable to alcohol consumption \\
\hline Alcohol dependence syndrome & $100 \%$ deaths attributable to alcohol consumption \\
\hline Alcoholic psychosis & $100 \%$ deaths attributable to alcohol consumption \\
\hline Alcoholic cardiomyopathy & $100 \%$ deaths attributable to alcohol consumption \\
\hline Alcoholic gastritis & $100 \%$ deaths attributable to alcohol consumption \\
\hline Assaults & $47 \%$ deaths attributable to alcohol consumption \\
\hline Accidental drowning & $31-50 \%$ deaths attributable to alcohol consumption (varies by age and sex ${ }^{\star \star}$ ) \\
\hline Accidental falls & $31-50 \%$ deaths attributable to alcohol consumption (varies by age and sex) \\
\hline Accidents caused by fire and flames & $44 \%$ deaths attributable to alcohol consumption \\
\hline Inhalation and ingestion & $5 \%$ deaths attributable to alcohol consumption $\dagger \dagger$ \\
\hline Occupational and machine injuries & $0-9 \%$ deaths attributable to alcohol consumption (varies by age and sex) \\
\hline Accidental poisoning by alcohol & $100 \%$ deaths attributable to alcohol consumption \\
\hline Motor vehicle accidents & $5-40 \%$ deaths attributable to alcohol consumption (varies by age and sex) \\
\hline Suicide & Relative risks of 1.40 for "low consumption", 2.32 for "hazardous consumption" and 2.52 for "harmful consumption" $\neq \ddagger$ \\
\hline
\end{tabular}

$\star$ alc $=$ alcohol dose in grams per day. †Corrao et al tested for interactions due to gender and where significant effects were found we have used the separate risk functions for men and women. ‡Corrao et al tested for interactions due to the area in which the study was performed. Where area effects were found, we used the nonMediterranean coefficient. \Corrao et al tested for study design interactions and when found we have used the cohort design model. ${ }^{\star \star}$ Further details are available

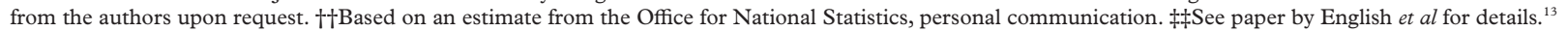

survey was based on a sample of approximately 16000 nationally representative men and women in which they were asked a series of questions designed to provide an estimate of average weekly consumption. Consumption among the Welsh population is very similar to the English population. ${ }^{12}$

The meta-analysis risk functions are given for an exposure measurement in grams of alcohol per day. It was therefore necessary to convert the Health Survey for England data (given in units of alcohol per week) by fitting a log normal distribution assuming one unit to be 8 grams of alcohol. This is shown in table 3.

Table 2 Alcohol consumption levels and relative risk of mortality from key alcohol related conditions

\begin{tabular}{lllllll}
\hline & None & $\begin{array}{l}1-10 \\
\text { g/day }\end{array}$ & $\begin{array}{l}10-20 \\
\text { g/day }\end{array}$ & $\begin{array}{l}20-30 \\
\text { g/day }\end{array}$ & $\begin{array}{l}30-40 \\
\text { g/day }\end{array}$ & $\begin{array}{l}40-50 \\
\text { g/day }\end{array}$ \\
\hline IHD men & 1 & 0.832 & 0.778 & 0.768 & 0.775 & 0.793 \\
IHD women & 1 & 0.857 & 0.853 & 0.896 & 0.962 & 1.047 \\
Colon cancer & 1 & 1.067 & 1.215 & 1.384 & 1.575 & 1.794 \\
Breast cancer & 1 & 1.039 & 1.122 & 1.211 & 1.308 & 1.412 \\
Haemorrhagic stroke & 1 & 1.078 & 1.252 & 1.455 & 1.690 & 1.964 \\
\hline
\end{tabular}

${ }^{\star}$ Midpoint in each category used to calculate relative risks.

Table 3 Distribution of alcohol consumption by age and sex, England 1998

\begin{tabular}{|c|c|c|c|c|c|c|c|}
\hline Gram/day & $16-24$ & $25-34$ & $35-44$ & $45-54$ & $55-64$ & $65-74$ & $75+$ \\
\hline \multicolumn{8}{|l|}{$\overline{M e n}$} \\
\hline None & 8 & 7 & 6 & 5 & 8 & 10 & 15 \\
\hline 1 to 10 & 25.1 & 29.3 & 29.4 & 29.6 & 33.9 & 39.6 & 48.8 \\
\hline 10 to 20 & 21.5 & 25.8 & 25.6 & 24.4 & 25.9 & 25.4 & 19.6 \\
\hline 20 to 30 & 13.7 & 14.5 & 14.5 & 14.5 & 13.5 & 11.7 & 8 \\
\hline 30 to 40 & 8.8 & 8.2 & 8.3 & 8.6 & 7.2 & 5.7 & 3.7 \\
\hline 40 to 50 & 5.8 & 5 & 5.1 & 5.4 & 4.1 & 3 & 1.9 \\
\hline 50 to 60 & 4 & 3.1 & 3.2 & 3.5 & 2.4 & 1.7 & 1.1 \\
\hline $\begin{array}{l}60+ \\
\text { Women }\end{array}$ & 13.1 & 7.1 & 7.9 & 9 & 5 & 2.9 & 1.9 \\
\hline None & 12 & 9 & 8 & 9 & 13 & 20 & 26 \\
\hline 1 to 10 & 48.2 & 56.1 & 59.7 & 58.7 & 68.9 & 62.1 & 60.7 \\
\hline 10 to 20 & 19.5 & 21 & 19.3 & 19.2 & 10.8 & 12.1 & 8.8 \\
\hline 20 to 30 & 8.5 & 7.4 & 6.8 & 6.9 & 4.4 & 3.5 & 2.5 \\
\hline 30 to 40 & 4.3 & 3.1 & 2.9 & 2.9 & 1.5 & 1.2 & 1 \\
\hline $40+$ & 7.5 & 3.4 & 3.3 & 3.3 & 1.4 & 1.1 & 1 \\
\hline
\end{tabular}

Data shown as percentages. Source: Adapted from Health Survey for England 1998 (Department of Health). Weekly amounts are averaged over drinking and non-drinking days.
The relative risks were applied to the consumption levels in each sex and age group and an attributable fraction obtained using:

Population attributable fraction (PAF) for exposures with multiple levels

$\mathrm{PAF}=\frac{\sum_{i=1}^{k} p i(R R i-1)}{\sum_{i=0}^{k} p i(R R i-1)+1}$,

where $R_{\mathrm{i}}=$ relative risk of mortality in exposed groups compared with unexposed group

$\mathrm{p}_{\mathrm{i}}=$ proportion of the population exposed in each group

$i=0$ to $\mathrm{K}$, where $i=0$ represents non-drinkers

The attributable fraction for a particular cause of death is the proportion of all deaths from that cause that can be attributed to current alcohol consumption (assuming the relative risks describe a causal relation) - that is, the proportion by which the mortality would be reduced if everybody became an abstainer from alcohol. Where there is a protective effect of alcohol the attributable fraction will be the increase as a proportion of the total that would result if everybody became an abstainer.

Where the development of a condition necessarily requires the consumption of alcohol (alcoholic liver disease ICD-9 571.0571.3; alcoholic gastritis ICD-9 535.3; accidental poisoning by alcohol ICD-9 E860.0, E860.1, E860.2; non-dependent abuse of alcohol 305.0; alcohol dependence syndrome 303; alcoholic psychosis 291; alcoholic cardiomyopathy 425.5) all reported deaths were assumed to be attributable to alcohol consumption.

A single risk function was estimated by Corrao et al for all injuries and adverse effects combined (ICD-9 800-999). We felt that it would be more informative from a public health perspective if separate component estimates were given for the proportion of alcohol 
Table 4 Alcohol attributable deaths by cause (>15 years), England and Wales, 1996

\begin{tabular}{|c|c|c|c|}
\hline & \multirow[b]{2}{*}{ Conditions } & \multicolumn{2}{|c|}{$\begin{array}{l}\text { Deaths attributable to alcohol/all } \\
\text { deaths }\end{array}$} \\
\hline & & Men & Women \\
\hline \multirow[t]{7}{*}{ Neoplasms } & Rectum cancer & $174 / 2819$ & $358 / 2136$ \\
\hline & Colon cancer & $934 / 5001$ & $401 / 5491$ \\
\hline & Oropharyngeal cancer & $356 / 874$ & $97 / 462$ \\
\hline & Laryngeal cancer & $74 / 635$ & 9/174 \\
\hline & Liver cancer & $108 / 1049$ & $36 / 766$ \\
\hline & Oesophageal cancer & $829 / 3567$ & $233 / 2268$ \\
\hline & Breast cancer & - & $667 / 12179$ \\
\hline \multirow[t]{4}{*}{ Circulatory } & Haemorrhagic stroke* & $598 / 2848$ & $426 / 4465$ \\
\hline & Essential hypertension & $12 / 64$ & $15 / 177$ \\
\hline & IHD & $-14485 / 70488$ & $-6813 / 58556$ \\
\hline & Alcoholic cardiomyopathy & $116 / 116$ & $24 / 24$ \\
\hline \multirow[t]{3}{*}{ Gastrointestinal } & Alcoholic liver disease & $1370 / 1370$ & $689 / 689$ \\
\hline & Chronic pancreatitis & $10 / 46$ & $2 / 32$ \\
\hline & Alcoholic gastritis & $3 / 3$ & $2 / 2$ \\
\hline \multirow[t]{9}{*}{ Injuries and adverse effects } & Assaults & $75 / 160$ & $24 / 50$ \\
\hline & Accidental drowning & $50 / 131$ & $16 / 43$ \\
\hline & Accidental falls & $486 / 1439$ & $690 / 2177$ \\
\hline & Accidents caused by fire/flames & $101 / 229$ & $77 / 176$ \\
\hline & Inhalation and ingestion & $6 / 127$ & $6 / 126$ \\
\hline & Occupational injuries & $4 / 63$ & $0 / 2$ \\
\hline & Accidental poisoning by alcohol & $13 / 13$ & $9 / 9$ \\
\hline & Motor vehicle traffic accidents & $654 / 2145$ & $104 / 803$ \\
\hline & Suicide & $797 / 2648$ & $200 / 794$ \\
\hline \multirow[t]{3}{*}{ Other alcohol essential } & $\begin{array}{l}\text { Non-dependent abuse of } \\
\text { alcohol }\end{array}$ & $100 / 100$ & $44 / 44$ \\
\hline & Alcohol dependence syndrome & $172 / 172$ & $78 / 78$ \\
\hline & Alcoholic psychosis & $10 / 10$ & $4 / 4$ \\
\hline Total & & -7433 & -2602 \\
\hline Deaths from all causes & & 261571 & 287796 \\
\hline$\%$ Alcohol attributable & & $-2.8 \%$ & $-0.9 \%$ \\
\hline
\end{tabular}

*The ICD-9 code for stroke is often "unspecified", therefore we have estimated the proportion of deaths that are of haemorrhagic origin using proportions form the Oxford Stroke Study (Bamford $\mathrm{J}$ et al. A prospective study of acute cerebrovascular disease in the community: the Oxfordshire Community Stroke Project 1981-1986. F Neurol Neurosurg Psychiatry 1990;53:16-22).

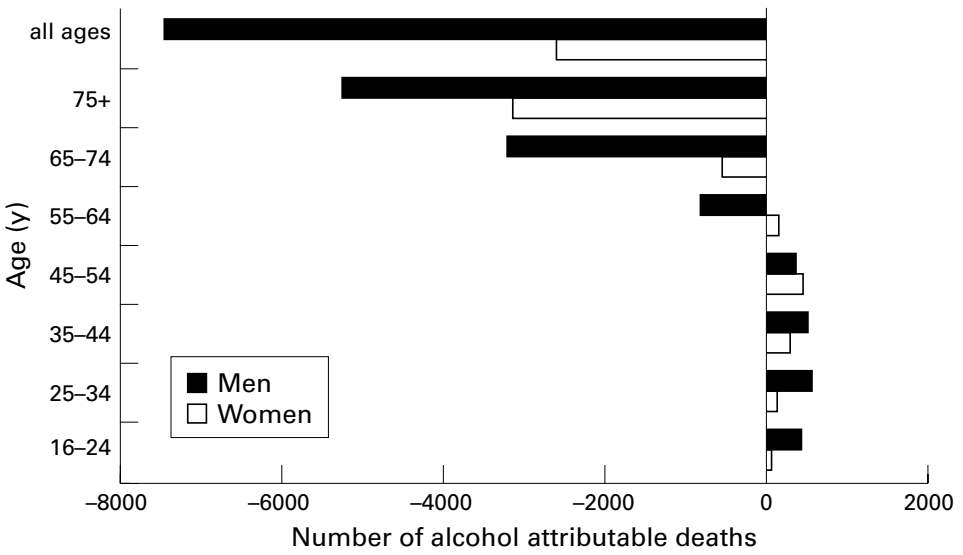

Figure 1 Net alcohol attributable deaths by age for adults in England and Wales 1996.

Table 5 Top three causes of alcohol related death by age in England and Wales, 1996

\begin{tabular}{|c|c|c|}
\hline Age group (y) & $\begin{array}{l}\text { Men (number of alcohol } \\
\text { attributable deaths) }\end{array}$ & $\begin{array}{l}\text { Women (number of alcohol } \\
\text { attributable deaths) }\end{array}$ \\
\hline \multirow[t]{3}{*}{$16-24$} & Road traffic accidents (249) & Road traffic accidents $(30)$ \\
\hline & Suicide (99) & Suicide (20) \\
\hline & Assaults (21) & Assaults (4) \\
\hline \multirow{3}{*}{$25-34$} & Suicide (214) & Suicide (42) \\
\hline & Road traffic accidents (198) & Road traffic accidents (36) \\
\hline & Alcoholic liver disease (49) & Alcoholic liver disease (18) \\
\hline \multirow[t]{3}{*}{$35-44$} & Alcoholic liver disease (233) & Alcoholic liver disease (127) \\
\hline & IHD (199 prevented) & Breast cancer (49) \\
\hline & Suicide (166) & Suicide (38) \\
\hline \multirow[t]{3}{*}{$45-54$} & IHD (847 prevented) & Alcoholic liver disease (213) \\
\hline & Alcoholic liver disease (445) & Breast cancer (129) \\
\hline & Suicide (152) & IHD (96 prevented) \\
\hline \multirow[t]{3}{*}{$55-64$} & IHD (2080 prevented) & IHD (389 prevented) \\
\hline & Alcoholic liver disease (357) & Alcoholic liver disease (161) \\
\hline & Colon cancer (190) & Breast cancer (114) \\
\hline \multirow[t]{3}{*}{$65-74$} & IHD (4609 prevented) & IHD (1343 prevented) \\
\hline & Colon cancer (314) & Breast cancer (144) \\
\hline & Oesophageal cancer (286) & Alcoholic liver disease (126) \\
\hline \multirow{3}{*}{$75+$} & IHD (6722 prevented) & IHD (4960 prevented) \\
\hline & Colon cancer (328) & Accidental falls (564) \\
\hline & Haemorrhagic stroke (283) & Haemorrhagic stroke (302) \\
\hline
\end{tabular}

attributable injury deaths. Therefore we based our estimates on those from an earlier metaanalysis of international literature by English et al ${ }^{13}$ for assaults (ICD-9 E960, E965, E966, E968, E969), accidental drowning (E910), accidental falls (E880-888), accidents caused by fire and flames (E890-899), inhalation and ingestion (E911), occupational and machine injuries $(\mathrm{E} 919,920)$, motor vehicle traffic accidents (E810-819) and suicide (E950-959).

The attributable fractions were then applied to the mortality data and an estimate was made of the number of alcohol attributed deaths "caused" or "prevented" by age and sex. These analyses adopt the most straightforward estimates of population attributable risk and ignore, in the interests of simplicity, any joint distribution of risk factors between several diseases. Data on these distributions are often sparse and varied. Moreover, as we are dealing with several different diseases that inevitably share some risk factors, for our purposes concentrating on just one risk factor, this simple univariate approach was considered to be an adequate compromise.

\section{Results}

The balance in terms of estimated numbers of deaths "prevented" and deaths "caused" by conditions associated with current levels of alcohol consumption, for all adults in England and Wales, is shown in table 4. For men, the net balance shows that, on aggregate, more deaths were "prevented" than were "caused" by alcohol consumption. This is because of the protective effect conferred by alcohol consumption on ishaemic heart disease. The risk function described by Corrao at al in their meta-analysis was such that the maximum benefit of about a $20 \%$ reduction of CHD risk was found in both men and women, but at lower consumption level for women (about $10 \mathrm{~g} /$ day for women and $25 \mathrm{~g} /$ day for men-see table 2). Harmful effects of alcohol on CHD risk were reported at about $40 \mathrm{~g}$ per day for women and $120 \mathrm{~g}$ per day for men, but the majority of the population do not drink at these levels (see table 3 ).

For both men and women, the net balance shows that there were slightly more deaths "prevented" than "caused". We estimate that there were approximately $2.8 \%$ fewer male deaths and $0.9 \%$ fewer female deaths in 1996 than would be expected in a non-drinking population.

For women of all ages combined, most alcohol attributable deaths are from accidental falls, alcoholic liver cirrhosis, breast cancer, haemorrhagic stroke and colon cancer. For men most alcohol related deaths are from alcoholic liver cirrhosis, colon cancer, oesophageal cancer, suicide and road traffic accidents.

The net balance of alcohol attributable deaths for each age group and by sex is shown in figure 1. It can be seen that not until age band 55-64 years (men) does the balance start to favour alcohol consumption.

Clearly the leading causes of alcohol associated deaths ("caused" or "prevented") change 
with age. The top three contributors for each age band are shown in table 5 .

Unsurprisingly, by far the majority of alcohol related deaths occur in the oldest age groups, reflecting the much higher incidences of such conditions. We are less confident of the accuracy of the relative risks in these age groups as the elderly are often excluded from studies. It could also be argued that the deaths "caused" or "prevented" by alcohol consumption at this age are of less interest in terms of population health than premature deaths. Therefore in addition to a quantification of deaths by age, the potential years of life lost or gained can provide a useful measure of the public health impact of alcohol consumption. The deaths at younger ages, mainly from injuries (accidental and intentional), contribute more to the total years of life lost, while the extra years gained from a protection from ischaemic heart disease contribute comparatively less. We estimate that there were 52412 male and 22724 female years of life lost up to age 65 (simply subtracting the age at which each death occurred from 65). The majority of these, particularly for the men, were attributable to premature deaths under age 44 years.

\section{Discussion}

We estimated that there were approximately $1.8 \%$ fewer deaths in England and Wales than would be expected in a non-drinking population. This estimate is lower than many of those obtained in previous attempts to quantify mortality attributable to alcohol consumption. In some instances this is because of the use of moderate drinking as the reference category and the calculation of deaths attributable to drinking more or drinking less than this amount. $^{1415}$

More often it is simply because most previous estimates did not include a protective role of alcohol. If the deaths prevented were ignored in this analysis, then approximately $2.0 \%$ of all mortality would be attributable to current alcohol consumption levels. This estimate is still lower than the estimate of $4.9 \%$ given by Schultz et al for the US population ${ }^{16}$ or $6.2 \%$ estimated by Sutocky et al for Californians. ${ }^{17}$ The WHO Global Burden of Disease report did incorporate the protective role of alcohol, but the authors still estimated that $1.2 \%$ of all deaths in the Established Market Economies are attributable to alcohol usethat is, a net protective estimate was not found. ${ }^{18}$ Single et al, in their study of the economic costs of drug use in Canada ${ }^{19}$ chose to use the relative risks derived by English et al's earlier meta-analysis ${ }^{13}$ and estimated that there was a higher number of deaths averted by the use of alcohol than the number of deaths caused by alcohol use. Duffy applied the all cause risk estimates from the British Regional Heart Study ${ }^{20}$ to 1987 population consumption data for men aged 45 to 64 years and also estimated that there were fewer deaths than would have occurred in an abstinent population. ${ }^{21}$ White et al recently applied the risk functions from Corrao et al's meta-analyses ${ }^{910}$ for 16 causes of death to the English and Welsh 1997
KEY POINTS

- In England and Wales alcohol consumption marginally reduces mortality at a population level.

- The favourable mortality balance from alcohol consumption is only found among men aged over 55 years and women aged over 65 years.

- More research is needed into the possible modifications by pattern and type of consumption, age and sex.

- Estimating alcohol attributable mortality by age and sex may be a useful indicator for developing alcohol strategies.

population and estimated that $0.8 \%$ of all deaths in men were prevented by alcohol consumption and $0.1 \%$ of all deaths in women were attributed to alcohol consumption. ${ }^{22}$ Therefore there is clearly still considerable controversy surrounding the quantification of alcohol attributable mortality, but the net protective estimate found in this analysis has been reported previously by others. The UK Government's green paper, Our Healthier Nation, ${ }^{23}$ quotes an estimated 40000 annual alcohol deaths (derived by the Royal College of General Practitioners, $1986^{24}$ ), which we believe to be an inaccurate and incomplete representation of the mortality consequences of alcohol consumption.

The deaths prevented occurred largely among those individuals in the oldest age groups, who had a much higher risk of ischaemic heart disease. The high burden of potential life lost among the young is of particular interest and emphasis should be placed on reducing the mortality in this section of the population, as well as reducing the larger numbers of deaths occurring among the older age groups. From this initial overall study of alcohol attributable mortality in England and Wales, it can be concluded that only for certain subgroups of the population, namely men aged over 55 years and women over 65 years, is there a net favourable mortality outcome from current consumption levels.

In the analyses described here we assume a causal relation between alcohol consumption and the various conditions. In a sensitivity analysis we excluded the large bowel cancers and breast cancer, as there is probably most controversy over the causal link with alcohol. ${ }^{25}{ }^{26}$ This restriction leads to an estimate of 12569 or $2.3 \%$ fewer deaths in 1996 than would be expected in a non-drinking population. In terms of person years of life lost this is 66400 years - that is, 8735 fewer years of life lost than when breast, colon and rectal cancer were included. The relation between alcohol and ischaemic stroke remains unclear and as Corrao et al's meta-analysis found a nonsignificant relation, we have not included ischaemic stroke in our estimates. Gastric and duodenal ulcers and acute pancreatitis are also not included in our calculations because the 
meta-analyses either failed to find any epidemiological evidence, or a non-significant relation with alcohol. The inclusion of these comparatively rare conditions would not change our overall conclusions.

The complete eradication of alcohol consumption will not be a target for any rational government. Therefore, in terms of a sensible drinking policy, it is useful to estimate the most beneficial drinking level in terms of lowest risk of death. This was recently estimated by White et al to be zero consumption at ages 16 to 34 years in men and at ages 16 to 54 years in women, rising with age to eight units ( 72 grams alcohol) per week in men aged over 65 years and three units (27 grams alcohol) per week in women aged over 65 years. ${ }^{22}$

LIMITATIONS AND FURTHER AREAS OF RESEARCH In this analysis we did not explore the consequences of different drinking patterns and behaviours that exist within a population. There is epidemiological and physiological evidence to suggest that the amount of alcohol consumed in one drinking session has an important impact on the subsequent health consequence. ${ }^{27}$ This is most apparent when considering alcohol and its relation with violence and accidents where an element of intoxication is assumed. However, "binge drinking" can have implications for the development of alcohol related diseases. For example, while the cardioprotective effect of alcohol is associated with moderate regular consumption, cardiovascular disease and sudden cardiac death have been shown to be associated with drinking in heavy, sporadic episodes. ${ }^{28} 29$

Another area of interest and some controversy, is the possible effect modification of beverage type. There has been considerable debate on whether the type of alcoholic drink confers different risks, for example, consumption of spirits or beer has been linked with an increased risk of cancer of the upper digestive tract compared with consumption of wine. ${ }^{30}$ However, an alternative explanation for the increase is that spirit and beer drinkers themselves have a different health profile or health behaviours to wine drinkers. ${ }^{31}$ Unfortunately neither the consumption data nor the relative risks used in this analysis were separated into beverage type.

The majority of the relative risks used in this analysis have not been modified according to age. This is largely because the data on which such modifications would be based are sparse. To assume that the relative risks apply to all ages for each disease equally may be an unreasonable assumption, but one commonly assumed in epidemiology. Where possible the relative risks used in this analysis incorporated gender effects. The gender effects, when included, showed positive coefficients, suggesting that women tend to experience consequences at lower doses than men.

The risk functions were derived from recent meta-analyses of the international literature. Caution arises when applying risk estimates to England and Wales based on other populations, ${ }^{32}$ however, using just evidence from the
UK would be severely restricting. Corrao et al tested for area effect modifications by separating studies into those from Mediterranean and non-Mediterranean countries. Significant effects were found for cancers of the oropharynx, oesophagus, larynx and breast and therefore for these deaths we used the risk function applicable to non-Mediterranean countries.

Where possible Corrao et al used studies in their meta-analysis that were adjusted for known confounders, particularly smoking for upper aerodigestive tract cancers, breast cancer and stroke. It is not possible to completely rule out the interaction between alcohol and other risk factors, however we have used the best estimates to our knowledge.

The population data on alcohol consumption are self reported and are therefore at risk of under-estimating or over-estimating actual consumption. It has been suggested that self reported alcohol use in population surveys covers only $40 \%-60 \%$ of alcohol sales, ${ }^{33}$ and individuals who are very heavy drinkers are unlikely to participate in the surveys. If the Health Survey for England underestimates the actual consumption, we will have underestimated the alcohol attributable deaths in this analysis. However, the estimated number of deaths from disorders such as alcoholic liver disease, alcoholic gastritis, poisoning by alcohol, etc, are taken from the Office for National Statistics and do not rely upon consumption estimates. On the other hand, it is possible that these official figures are affected by underreporting, for example by coroners to protect families.

This analysis focuses on current consumption and does not consider previous levels or patterns of drinking. It is probable that an exposure over several years is needed for some conditions to develop and more longitudinal studies are needed in which changes in alcohol consumption are measured. However, this study does identify the sex and age groups for which alcohol has substantial negative consequences in terms of mortality and years of life lost and this information could be used to target prevention strategies.

While the debate on the relation between alcohol consumption and mortality from certain causes is still on the agenda, and particularly in light of recent epidemiological evidence that challenges alcohol's cardioprotective properties, ${ }^{34}$ we believe our estimations could help inform policy decisions for the forthcoming English national alcohol strategy. ${ }^{35}$

The authors are grateful for helpful comments from Franco Cavallo, Morten Grønbæk, Ian Macdonald, John Powles, Ron Simpson and Ian White.

Funding: unconditional grant from International Life Sciences

Institute (ILSI-Europe).
Conflicts of interest: none.

1 Doll $\mathrm{R}$, Peto $\mathrm{R}$, Hall $\mathrm{E}$, et al. Mortality in relation to consumption of alcohol: 13 years' observations on male British doctors. BMF 1994;309:911-18.

2 Camargo CA. Moderate alcohol consumption and stroke: the epidemiological evidence. Stroke 1989;20:1611-26.

3 Stampfer MJ, Colditz GA, Willett WC, et al. A prospective study of moderate alcohol consumption and the risk of coronary disease and stroke in women. $N$ Engl f Med 1988;319:267-73. 
4 Thun MJ, Peto R, Lopez AD, et al. Alcohol consumption and mortality among middle-aged and elderly U.S. adults. $N$ Engl f Med 1997;337:1705-14

5 Fuchs CS, Stampfer MJ, Colditz GA, et al. Alcohol consumption and mortality among women. $\mathrm{N} \mathrm{Engl} \mathcal{F} \mathrm{Med}$ 1995;332:1245-50.

6 Smith-Warner SA, Spiegelman D, Yaun SS, et al. Alcohol and breast cancer in women: a pooled analysis of cohort studies. FAMA 1998;297:535-40

7 Brodsky A, Peele S. Psychosocial benefits of moderate alcohol consumption: alcohol's role in a broader conception of health and well-being. In: Peele S, Grant M, eds. Alcoho and pleasure: $a$ health perspective. Philadelphia: Taylor and Francis, 1999:187-207.

8 Office for National Statistics. Twentieth century mortality $C D$ ROM. London: 1997.

9 Corrao G, Bagnardi V, Zambon A, et al. Exploring the doseresponse relationship between alcohol consumption and the risk of several alcohol-related conditions: a metaanalysis. Addiction 1999;94:1551-73

10 Corrao G, Rubbiati L, Bagnardi V, et al. Alcohol and coronary heart disease: a meta-analysis. Addiction 2000;95:1505-23

11 Erens B, Primatesta P, eds. Health survey for England 1998 London: The Stationery Office, 1999

12 Bridgwood A, Lilly R, Thomas M, et al. Living in Britain: results from the 1998 General Household Survey. London: The Stationery Office, 2000

13 English DR, Holman CCDJ, Milne E, et al. The quantification of drug caused morbidity and mortality in Australia. Canberra: Commonwealth Department of Human Services, AGPS, 1995

14 Anderson P. Excess mortality associated with alcohol consumption. BM7 1988;297:824-6.

15 White I, Britton A, Nanchahal K, et al. Mortality attributable to drinking, drinking too much, or drinking too little: a comparison of methods. F Public Health Med 1999;21:407-11.

16 Schultz JM, Rice DP, Parker DL. Alcohol-related mortality and years of potential life lost - United States, 1987. Mor bidity and Mortality Weekly Report 1990;39:173-8.

17 Sutocky JW, Schultz JM, Kizer KW. Alcohol-related mortality in California, 1980 to 1989. Am f Public Health 1993;83:817-23.

18 Murray CJL, Lopez AD, eds. Global burden of disease Boston: Harvard School of Public Health on behalf of World Health Organisation and World Bank, 1996.
19 Single E, Robson L, Xie X, et al. The economic costs of alcohol, tobacco and illicit drugs in Canada, 1992 . Addiction 1998;93:991-1006.

20 Shaper AG, Wannamethee G, Walker M. Alcohol and mortality in British men: explaining the U-shaped curve. Lancet $1988 ; 2: 1267-73$

21 Duffy JC. Alcohol and All-cause Mortality. In: Duffy JC, ed. Alcohol and illness: the epidemiological viewpoint. Edinburgh, Scotland: Edinburgh University Press, 1992:26-35.

22 White IR, Altmann DR, Nanchahal K. 'Optimal' levels of alcohol consumption for men and women at different ages, and the all-cause mortality attributable to drinking. Technical report. London: London School of Hygiene and Tropical Medicine, 2000

23 Department of Health. Our healthier nation: A contract for health. London: The Stationery Office, 1998.

24 Royal College of General Practitioners. Alcohol - a balanced view. London: RCGP, 1986.

25 McPherson K, Cavallo F, Rubin E. Alcohol and breast cancer. In: Macdonald I, ed. Health issues related to alcohol consumption. London: Blackwell, 1999:214-42.

26 Plant ML Alcohol and breast cancer: a review. International fournal of Addictions 1992;27:107-28.

27 Grant M, Litvak J, eds. Drinking patterns and their consequences. Washington: Taylor and Francis, 1988.

28 McKee M, Britton A. The positive relationship between alcohol and heart disease in Eastern Europe: potential physiological mechanisms. F Roy Soc Med 1998;91:402-7.

29 Britton A, McKee M. The relation between alcohol and cardiovascular disease in Eastern Europe: explaining the paradox. F Epidemiol Community Health 2000:54:328-32.

30 Grønbaek M, Becker U, Johansen D, et al. Population based cohort study of the association between alcohol intake and cancer of the upper digestive tract. BMF 1998;317:844-8.

31 Tjønneland A, Grønbaek M, Stripp C, et al. Wine intake and diet in a random sample of 48763 Danish men and women. Am Clin Nutr 1999;69:49-54.

32 Duffy JC. Alcohol and all-cause mortality. In: Alcohol and illness: the epidemiological viewpoint. Edinburgh, Scotland: Ediness: the epidemiological viewpoint. Ed

33 De Fries JHM, Lemmens PHHM, Pietinen, P, et al. Assessment of alcohol consumption. In: Macdonald I, ed. Health issues related to alcohol consumption. London: Blackwell, 1999:27-62.

34 Hart CL, Davey Smith G, Hole DJ, et al. Alcohol consumption and mortality from all causes, coronary heart disease, and stroke: results from a prospective cohort study of Scottish men with 21 years of follow up. BMF 1999;318:1725-9

35 Department of Health. Saving lives: our healthier nation. London: The Stationery Office, 1999.

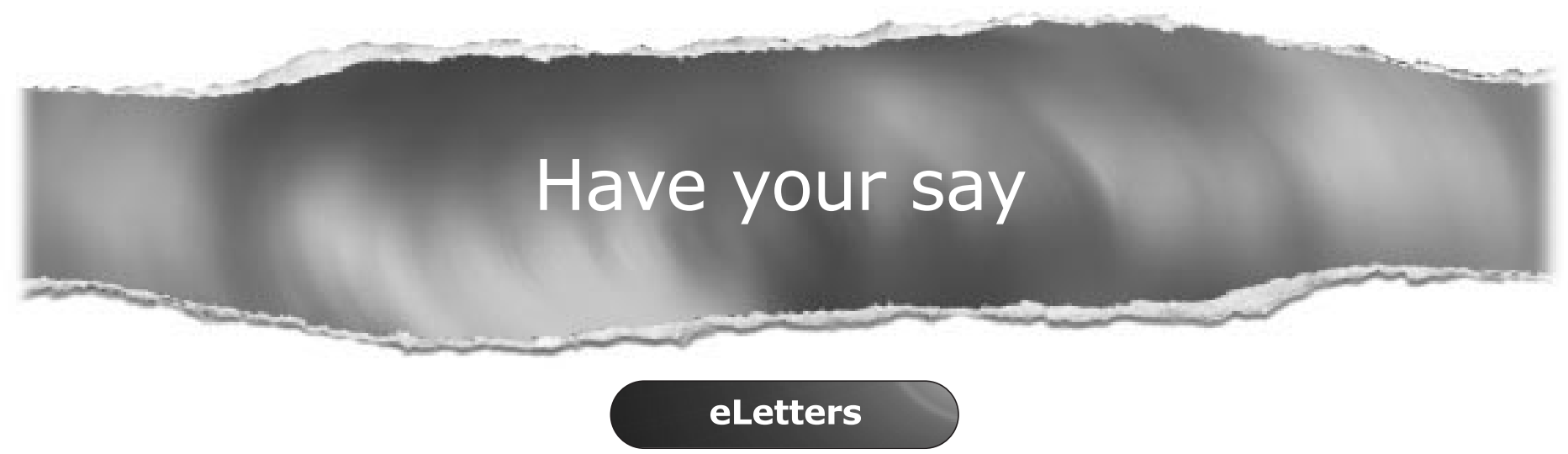

If you wish to comment on any article published in the Journal of Epidemiology and Community Health you can send an eLetter using the eletters link at the beginning of each article. Your response will be posted on Journal of Epidemiology and Community Health online within a few days of receipt (subject to editorial screening).

www.jech.com 